\title{
On the Road to Leucine-Rich Repeat Kinase 2 Signalling: Evidence from Cellular and in vivo Studies
}

\author{
V. Daniëls V. Baekelandt J.-M. Taymans \\ Laboratory for Neurobiology and Gene Therapy, Katholieke Universiteit Leuven, Leuven, Belgium
}

\section{Key Words}

Neurodegenerative disease - Parkinson's disease •

Signalling $\cdot$ Mitogen-activated protein kinase $\cdot$ GTPase $\cdot$

Cytoskeleton dynamics $\cdot$ Apoptosis

\begin{abstract}
Parkinson's disease (PD) is the most common neurodegenerative movement disorder. Although PD has long been considered a purely sporadic disorder, genetic research has revealed an underlying genetic cause in at least $10 \%$ of all PD cases. To date, mutations in the leucine-rich repeat kinase 2 (LRRK2) gene are the most common cause of familial PD. Moreover, given the strong clinical and neuropathological similarities between LRRK2 PD and the sporadic forms of the disease, the notion is supported that the unravelling of the molecular pathways underlying LRRK2 PD will greatly contribute to our general understanding of PD. Therefore, intense research efforts have been focused on the understanding of the physiological function of LRRK2 and its relation to PD. To date, progress has been made in these fields based on the study of LRRK2 cell culture models, the identification of LRRK2 interaction partners and kinase substrates and the generation of LRRK2 animal models. In this review, the current insights into the cellular role of LRRK2 are dis-
\end{abstract}

\section{KARGER}

Fax +4161306 1234

E-Mail karger@karger.ch

www.karger.com (c) 2011 S. Karger AG, Basel

1424-862X/11/0191-0001\$38.00/0

Accessible online at:

www.karger.com/nsg cussed. The overview reveals a potential involvement of LRRK2 in major cell signalling pathways including apoptosis, cytoskeleton dynamics, protein translation, mitogen-activated protein kinase signalling and specific dopaminergic functions, consistent with its proposed role as a signal transduction protein.

Copyright $\odot 2011$ S. Karger AG, Basel

\section{Introduction}

The leucine-rich repeat kinase 2 (LRRK2) gene encodes a complex ROCO protein encompassing several protein interaction motifs and a catalytic core region featuring two enzymatically active domains, i.e. a Ras of complex proteins (ROC) GTPase domain and a kinase domain, linked by the C-terminal of ROC (COR) domain (fig. 1).

To gain insight into the causal relation between LRRK2 mutations and Parkinson's disease (PD), it is crucial to know the answer to the following two questions: first, what is the normal function of LRRK2 in the brain? Second, how is this function altered by pathogenic LRRK2 mutations? The answer to the latter question is confounded by the large number of mutations in different domains

Jean-Marc Taymans

Laboratory for Neurobiology and Gene Therapy, Katholieke Universiteit Leuven Kapucijnenvoer 33, VCTB +5

BE-3000 Leuven (Belgium)

Tel. +32 1633 2194, E-Mail jean-marc.taymans@med.kuleuven.be 


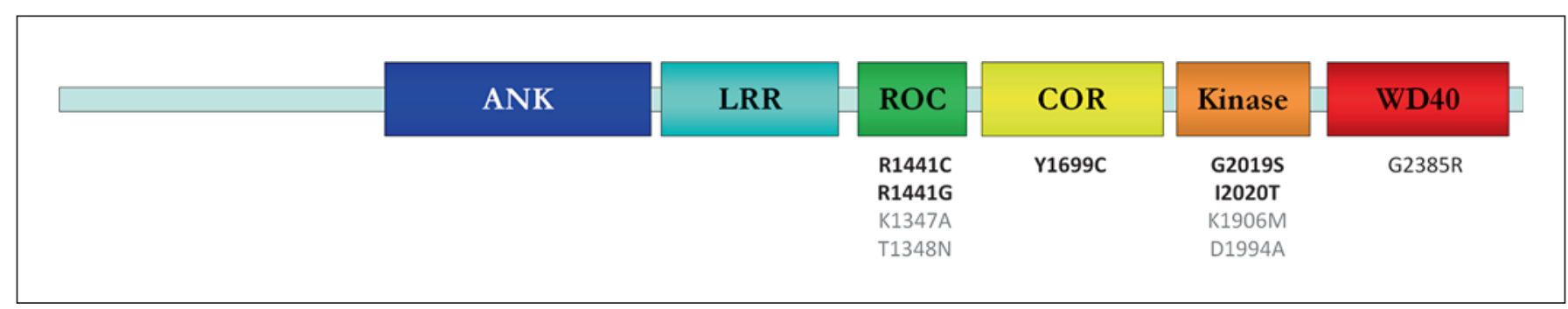

Fig. 1. Schematic representation of the domain structure of LRRK2. Amino acid substitutions are depicted below the structure: pathogenic mutations in bold; risk variant in black; functional mutations in grey. ANK = Ankyrin repeat domain of LRRK2; LRR = leucine-rich repeat.

of the protein, the considerable neuropathological heterogeneity of LRRK2 patients and the incomplete penetrance in LRRK2 mutation carriers. Therefore, a third question may be added: how are LRRK2 mutational effects influenced by secondary factors, such as environmental and genetic factors? To find the answers to these three questions, three major routes have been explored: first, overexpression and knockdown of LRRK2 in cell culture systems; second, the search for cellular pathways in which LRRK2 is involved mainly via the identification of LRRK2 substrates and interacting partners, and third, the development of LRRK2 animal models. These three approaches will be further discussed in detail in this review, with a focus on signalling processes and cascades potentially involving LRRK2.

\section{Overexpression and Knockdown of LRRK2 in Cell Culture Systems}

To date, several research groups have assessed the effects of knockdown of LRRK2 or overexpression of both wild-type (wt) and mutant forms in cell culture systems. These experiments have yielded important clues to the potential involvement of LRRK2 in specific cellular processes.

\section{Cell Viability}

A graphical overview of published effects of LRRK2 overexpression on cell viability in cultured cells and neurons is given in figure 2. In most cases, overexpression of wt LRRK2 causes a (mild) reduction in cell/neuron viability ranging from 10 up to $40 \%$. In all reports, introduction of the pathogenic mutants R1441C, I2020T and G2019S causes a 3- to 5-fold increase in cell toxicity, whereas the effect of the Y1699C mutant is somewhat milder: only a 2- to 3-fold increase in cell toxicity relative to wt LRRK2. It should be noted that the mutant effect of LRRK2 can be more pronounced in neuronal cells since Liou et al. [1] have reported no differential effects between wt LRRK2 and mutants in HEK293T cells, whereas in SH-SY5Y cells, a 20\% reduction in cell viability was observed after overexpression of mutant LRRK2 in comparison with wt LRRK2.

The observed cellular toxicity induced by overexpression of LRRK2 is at least in part dependent on the presence of a functional kinase and/or GTPase domain. Both deletion of the kinase domain [1] or expression of wt and mutant LRRK2 in a kinase- or GTPase-dead background [2-5] attenuate LRRK2-induced cell toxicity. Moreover, LRRK2 pathogenic mutants that have been shown to reduce cell viability after overexpression are all associated with an alteration in LRRK2 kinase or GTPase activity: the G2019S mutant, and to a lesser extent also the I2020T mutant, increase the kinase activity of the full-length protein $[4,6]$, whereas both R1441C and Y1699C mutants are associated with reduced LRRK2 GTPase activity [710]. For these latter mutations, we and others have shown that these lead to an altered organisation of the catalytic core of LRRK2 [10, 11]. The notion that LRRK2-induced cytotoxicity is linked to its kinase activity is supported by a recent report by Lee et al. [5]. The authors show that cytotoxicity induced by overexpression of the G2019S mutant can be significantly attenuated by administration of inhibitors of LRRK2 kinase activity. Although the latter study convincingly supports a causal link between G2019S LRRK2-induced cytotoxicity and increased kinase activity, no absolute causal interdependence between wt LRRK2-induced cellular toxicity and its kinase activity could be confirmed to date [12]. Another pending issue is the exact contribution of the different LRRK2 domains to LRRK2-induced cellular toxicity. One study has 


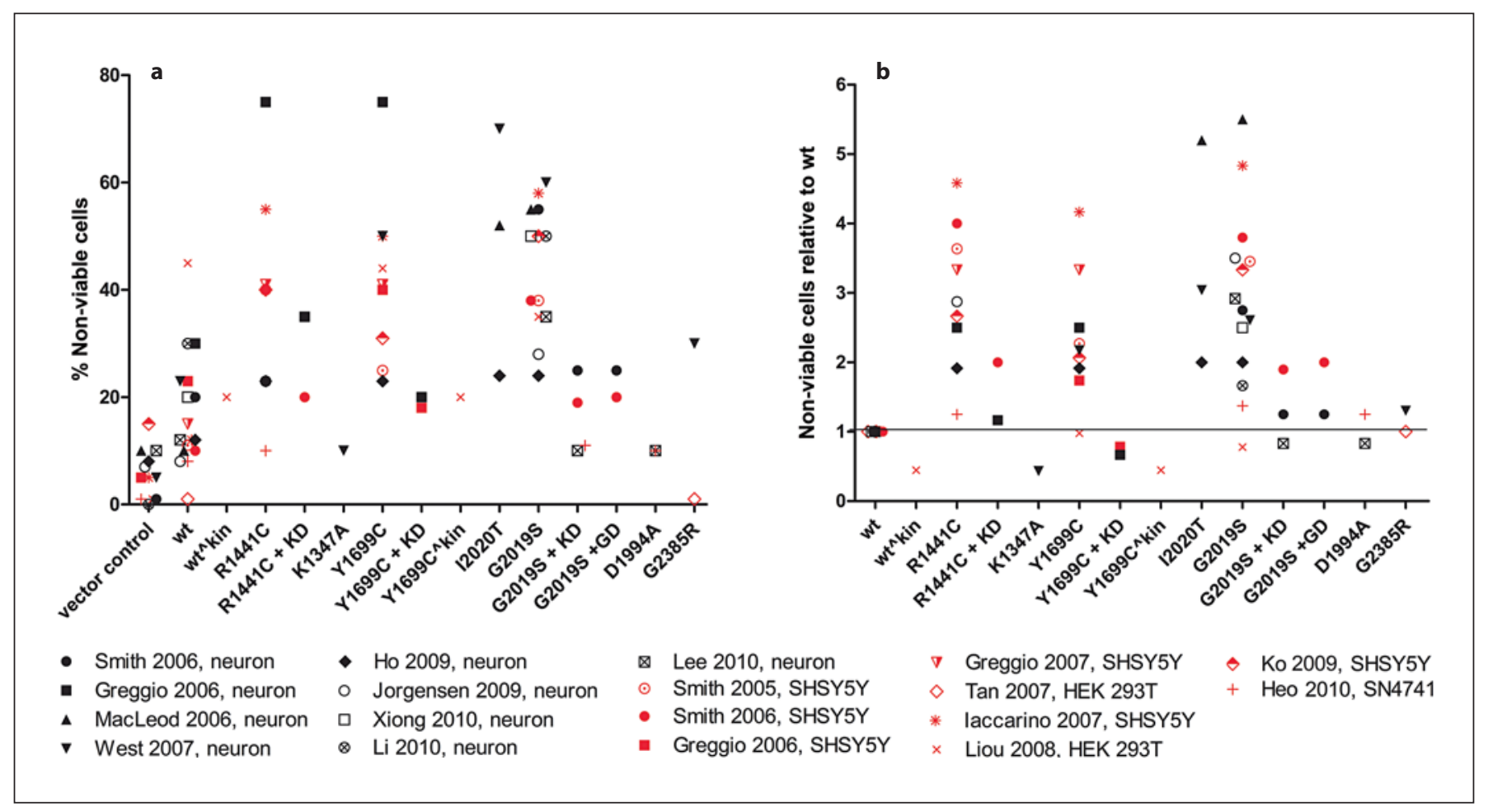

Fig. 2. Effect of LRRK2 overexpression on cell viability in cultured cells and neurons. $\wedge$ kin $=$ Deletion of the kinase domain; $\mathrm{KD}$ = kinase dead; GD = GTPase dead. The legend displays the first author and year of the report as well as the cell type tested. Black: tests performed in primary neuron culture. Red: tests in immortalised cells. a Representation of the percentage of non-viable cells/neurons observed following overexpressing LRRK2 wt and mutants as reported in the literature. $\mathbf{b}$ Cell viability of mutant LRRK2 normalised to the viability of cells/neurons overexpressing wt LRRK2, for each literature report.

shown that overexpression of the isolated kinase domain, the ROC-COR-kinase (RCK) fragment or the RCKWD40 fragment, each wt, G2019S and R1441C, is sufficient to reduce cell viability comparable to the full-length protein [13]. However, it should be noted that these observations could only be made after application of oxidative stress, which has been shown to dramatically reduce the cell viability of LRRK2-overexpressing cells [4]. In another study, overexpression of the RCK fragment or the ROC domain in yeast cells or neurons caused a drop in viability, whereas a viability drop was less pronounced or even absent in yeast cells and neurons, respectively, overexpressing the isolated kinase domain. Furthermore, the cytotoxic effect of RCK overexpression in yeast was increased in a GTPase-dead background or after introduction of the R1441C mutant, which has consistently been shown to reduce LRRK2 GTPase activity, whereas it could be attenuated by the introduction of artificial GTPase-stimulating mutations (T1343G/R1398Q or
R1398L). In neuronal cultures, however, only the augmentation of the cytotoxic effect of the GTPase-dead RCK mutants could be replicated [9]. Hence, the precise contribution of the kinase and GTPase domains/functions to LRRK2-induced cellular toxicity is still incompletely understood.

Finally, it has been shown that deletion of the leucinerich repeat (LRR) or WD40 domains can rescue G2019S and/or R1441C mutant LRRK2-induced cytotoxicity in neuronal cells $[14,15]$. However, the underlying cause is not clear and could be related to a disrupted protein conformation, the absence of an important protein-protein interaction domain, as are LRR and WD40 domains, and/or an alteration to the biochemical properties of the truncated protein in comparison with the full-length protein.

Several lines of evidence suggest that LRRK2-induced cytotoxicity is in part mediated by an apoptotic process [14, 16-18]. Iaccarino et al. [14] have shown that transient 
transfection of mutant LRRK2 induces apoptosis via the intrinsic cell death pathway involving cytochrome $c$ release and caspase 3 activation. On the other hand, Ho et al. [16] have shown that LRRK2 can effectuate cell death via the extrinsic apoptotic pathway by interaction with Fas-associated protein with death domain (FADD) and activation of caspase 8 . Moreover, pathogenic mutations in LRRK2 (R1441C, Y1699C, I2020T, G2019S) that enhance LRRK2-mediated cytotoxicity also enhance the interaction with FADD in comparison with the wt protein. This mutant effect was abolished in a kinase-dead background. The strength of the interaction between LRRK2 and FADD does not seem to be linearly related to LRRK2 kinase activity or LRRK2-induced cytotoxicity since the enhanced interaction between LRRK2 and FADD was less pronounced for the G2019S mutant. Moreover, both R1441C and Y1699C mutants, which strongly enhanced the interaction with FADD, have not consistently been shown to upregulate LRRK2 kinase activity.

Finally, despite all reports on LRRK2-induced cytotoxicity mentioned above, several recent observations, including our own unpublished results, point to secondary effects which might contribute to the observed effects on cell viability caused by overexpression of LRRK2. These factors include the level of LRRK2 overexpression [19], the cell type used [1], the nature of the LRRK2 expression construct, including the type and position of an eventual tag [20] (own observations), and the experimental setup (own observations).

\section{Neurite Process Morphology}

Overexpression of pathogenic LRRK2 mutants is consistently associated with shorter neurites in both primary neurons and differentiated SH-SY5Y cells [5, 9, 17, 21-23]. On the other hand, a reduction in LRRK2 expression or LRRK2 protein levels by LRRK2 knockdown and Heat shock protein 90 (Hsp90) inhibitors, respectively, has been found to result in increased neurite length [17, 22, 23]. In primary neurons, the underlying mechanism seems to be mediated in part by LRRK2 kinase activity: overexpression of the K1906M kinase-dead LRRK2 mutant caused an increase in neurite process length both in a wt and G2019S mutant background [17, 23]. Moreover, MacLeod et al. [17] have reported that the isolated kinase domain, both wt and G2019S mutant, is sufficient to induce neurite shortening in primary neurons. Although the precise underlying mechanism of LRRK2-mediated neurite process morphology is not yet clear, several potential mechanisms have been proposed based on experimental observations: impairment of the lysosomal pathway [17], dysregulation of autophagy [21], defects in both synaptic vesicle endocytosis and exocytosis [9], and rearrangement of the actin cytoskeleton by alteration to the phosphorylation of ezrin/ radixin/moesin (ERM) proteins [23]. Very recent evidence also points towards an involvement of the microtubuleassociated protein tau in this process [24].

\section{LRRK2 Aggregate Formation}

Several authors have reported the presence of perinuclear, LRRK2-positive inclusions in cultured cells and primary neurons after transient transfection of LRRK2 mutants and, to a lesser extent, also of LRRK2 wt $[3,17-$ 19, 25-31]. In some cases, colocalisation of these inclusion bodies with aggresome markers $[3,26]$, phosphorylated tau [17] or autophagy markers [27] has been described. Colocalisation of these LRRK2-positive aggregates with $\alpha$-synuclein has never been found under basal conditions [17, 25, 26, 32]. However, Qing et al. [32] have reported colocalisation of both proteins after coexpression in HEK293T cells under oxidative stress. Whether LRRK2 aggregate formation is a true (patho)physiological process rather than a consequence of overexpression is not clear to date. On the one hand, LRRK2 has only been found in $10-15 \%$ of Lewy bodies (LB) in postmortem analysis of LRRK2 PD patients, whereas LRRK2 aggregates, as described in cell culture, have not been reported in humans so far. On the other hand, two recent studies point towards an important regulatory function of 14-3-3 proteins in the cytoplasmic distribution of LRRK2, which is affected by several disease-causing LRRK2 mutations $[30,31]$. In essence, the data support a scenario in which binding of 14-3-3 isoforms is mediated by phosphorylation of LRRK2, most likely by another kinase, at two conserved residues located before the LRR domain ( $\mathrm{Ser}^{910}$ and $\mathrm{Ser}^{935}$ ). A reduction or abolishment of the phosphorylation of these residues leads to a reduction or abolishment of the interaction between LRRK2 and 14-3-3 isoforms and the formation of cytoplasmic LRRK2 aggregates. Some notable exceptions to the finding that LRRK2 mutants show reduced 14-3-3 binding and form cytoplasmic inclusions are the pathogenic LRRK2 mutants G2019S, I2012T, I1371V and T2356I. Therefore, the relevance of the interaction of LRRK2 with 14-3-3 for PD pathology requires further investigation. Nevertheless, the in-depth study of the interaction of LRRK2 with 143-3 might provide important insight into the regulation of LRRK2, as well as potentially point to mutant-specific mechanisms [33].

In conclusion, transient overexpression of LRRK2 $\mathrm{wt}$ and pathogenic mutants in cell culture systems has re- 
vealed a role for LRRK2 in apoptotic cell death and neurite outgrowth via a potential involvement in autophagy, synaptic vesicle endo-/exocytosis, the lysosomal degradation pathway and the modelling of the actin cytoskeleton. However, caution is warranted in the interpretation of these cell culture experiments since most of these experimental data have been obtained after transient overexpression of high levels of LRRK2. This concern is supported by a recent report by Dächsel et al. [34], in which the authors show that the LRRK2-related neuritic phenotype is dependent on LRRK2 expression levels: primary neuron cultures derived from bacterial artificial chromosome (BAC) transgenic G2019S or Y1699C mice presented with significantly reduced neuritic outgrowth, whereas neuronal cultures derived from G2019S knockin mice displayed no abnormalities. Nevertheless, the observed neuritic phenotype in neuronal cultures from BAC transgenic mice seemed to be mutant specific [34]. Therefore, differences in expression levels and protein stability may bias the experimental outcome, and may in particular confound the elucidation of the contribution of each pathogenic mutant to a specific alteration in LRRK2 function(s). For example, it has been shown that the I2020T LRRK2 mutant increases LRRK2 kinase activity $[4,6,35]$. However, this mutant has also been found to have a higher intracellular degradation rate in comparison with the wt protein [36]. Therefore, it is not clear whether the increase in kinase activity per se is responsible for the observed drop in cell viability and neurite length or whether protein stability is a more important contributing factor, or even a combination of both. Also, the GTPase-dead K1347A mutant has been described to dramatically destabilise the LRRK2 protein [8]. Therefore, the unravelling of the relationship between LRRK2 biochemical properties and its cellular functions might not be so straightforward.

\section{The Search for LRRK2 Interaction Partners and Substrates}

By the identification of LRRK2-interacting proteins and potential kinase substrates of LRRK2, the protein has been implicated in several cellular processes overviewed in table 1.

\section{LRRK2 2 and the Chaperone Machinery}

LRRK2 interacts with proteins associated with the chaperone machinery, including Hsp90, the Hsp90 cochaperone $\mathrm{p} 50^{\mathrm{CDC} 37}$ and the C-terminus of Hsp70-inter- acting protein (CHIP) [6, 20, 22, 37-39]. The interaction between LRRK2 and Hsp90 has been reported both in vitro in LRRK2-transfected HEK293T cells $[6,20]$ and in a yeast two-hybrid assay [39] as well as in vivo [22]. This interaction is mediated by both the kinase domain and the N-terminal region of LRRK2. Hsp90 interacts with several protein kinases to assist in their proper folding, including LRRK2 since functional Hsp90 protects LRRK2 against proteasomal degradation [22]. Moreover, Hsp90 inhibitors have been shown to rescue the shortened neurite phenotype in LRRK2 G2019S-expressing neurons, which is most likely related to a reduction of LRRK2 protein levels in these cells [22, 23].

Hsp90 is also a crucial component of the LRRK2CHIP protein complex. Co-immunoprecipitation and yeast two-hybrid data have indicated that the ROC domain of LRRK2 can bind to the tricopeptide domain of CHIP independent of Hsp90. However, the interaction between the N-terminal part of LRRK2 and CHIP requires functional Hsp90. The E3 ubiquitin ligase CHIP regulates LRRK2 protein levels via proteasomal degradation, mediated by its ubiquitination activity. This functional relation between LRRK2 and CHIP is CHIP-dose dependent but independent of pathogenic LRRK2 mutations or LRRK2 kinase activity [38, 39]. Ko et al. [38] have shown that overexpression of CHIP protects against, and knockdown of CHIP exacerbates, mutant LRRK2-mediated toxicity in both $\mathrm{SH}-\mathrm{SY} 5 \mathrm{Y}$ cells and primary neurons. However, in this study, knockdown of CHIP in LRRK2 wt-overexpressing cells resulted in a similar drop in viability as was observed in the LRRK2 mutant lines [38]. Therefore, it cannot be stated with certainty that the functional interaction between LRRK2 and Hsp90/CHIP is differentially influenced by LRRK2 pathogenic mutations, and therefore might contribute to pathogenic LRRK2-mediated PD. On the other hand, these findings support the notion that LRRK2 protein levels per se contribute to the observed cellular effects of LRRK2.

\section{LRRK2 and the Cytoskeleton}

LRRK2 interacts with $\alpha / \beta$-tubulin heterodimers and $\beta$-tubulin both in vitro and in vivo $[6,40,41]$. The interaction is mediated by the ROC domain of LRRK2 in a nucleotide-independent manner and is not influenced by the R1441C ROC mutation [42]. Gillardon [41] has shown that LRRK2 preferentially phosphorylates $\beta$-tubulin. This phosphorylation was enhanced by G2019S LRRK2. The elevated levels of phosphorylated $\beta$-tubulin resulted in increased microtubule stability in the presence of microtubule-associated proteins in an in vitro assay. There- 
Table 1. Overview of pathways in which LRRK2 is implicated

\begin{tabular}{|c|c|c|c|c|c|c|}
\hline & Link with LRRK2 & $\mathrm{I} / \mathrm{P} / \mathrm{GI}$ & $\begin{array}{l}\text { LRRK2 } \\
\text { fragment }\end{array}$ & Method & $\begin{array}{l}\text { Mutant effect on } \mathrm{I} / \mathrm{P} / \\
\text { GI compared to wt }\end{array}$ & $\begin{array}{l}\text { Refer- } \\
\text { ence No. }\end{array}$ \\
\hline \multirow[t]{2}{*}{$\begin{array}{l}\text { Chaperone } \\
\text { machinery }\end{array}$} & Hsp90 & I & FL, kin, N-term & $\begin{array}{l}\text { Co-IP (HEK293T cells, } \\
\text { mouse brain), YTH }\end{array}$ & GS - & $\begin{array}{l}{[20,22} \\
37-39]\end{array}$ \\
\hline & $\mathrm{p}^{5} 0^{\mathrm{CDC} 37}$ & I & FL, kin & $\begin{array}{l}\text { Co-IP (HEK293T cells, } \\
\text { mouse brain) }\end{array}$ & NA & {$[6,22]$} \\
\hline \multirow[t]{4}{*}{ Cytoskeleton } & $\alpha$-tubulin & I & FL, ROC & pulldown & $\mathrm{RC}-$ & {$[40]$} \\
\hline & $\beta$-tubulin & $\mathrm{I} / \mathrm{P}$ & FL, ROC & $\begin{array}{l}\text { Co-IP (HEK293T cells, } \\
\text { mouse brain), pulldown }\end{array}$ & $\mathrm{I}: \mathrm{RC}, \mathrm{GS}-$ & {$[40,41]$} \\
\hline & EF1A & I & FL & $\begin{array}{l}\text { copurification (insect cells), } \\
\text { Co-IP (HEK293T cells) }\end{array}$ & GS - & {$[42]$} \\
\hline & $\begin{array}{l}\text { actin cytoskeleton } \\
\text { (related) proteins }\end{array}$ & I & FL & QUICK, Co-IP (NIH3T3 cells) & NA & {$[44]$} \\
\hline $\begin{array}{l}\text { Protein } \\
\text { translation }\end{array}$ & $4 \mathrm{E}-\mathrm{BP}$ & $\mathrm{P} / \mathrm{GI}$ & & in vitro, Drosophila & & {$[45,46]$} \\
\hline \multirow[t]{2}{*}{ Apoptosis } & FADD & I & FL & $\begin{array}{l}\text { Co-IP (HEK } 293 \text { T cells, } \\
\text { mouse brain) }\end{array}$ & RC, YC, IT, GS $\uparrow$ & {$[16]$} \\
\hline & TRADD, RIP1 & I & FL & Co-IP (HEK293T cells ) & RC, YC, IT, GS - & {$[16]$} \\
\hline $\begin{array}{l}\text { Synaptic vesicle } \\
\text { endocytosis }\end{array}$ & Rab5b & I & FL, LRR & YTH, pulldown, Co-IP & $\mathrm{RC}, \mathrm{GS}-$ & {$[19]$} \\
\hline \multirow{2}{*}{$\begin{array}{l}\text { MAPK } \\
\text { signalling }\end{array}$} & JIP1-3 & I & FL & Co-IP (HEK293T cells ) & NA & [49] \\
\hline & JIP4 & I & FL & Co-IP (HEK293T cells ) & GS, RC, IT $\uparrow ;$ YC $\downarrow$ & [49] \\
\hline Cell signalling? & $14-3-3$ isoforms & I & FL & $\begin{array}{l}\text { Co-IP (HEK293T cells, Swiss } 3 \text { T3 } \\
\text { cells, mouse brain, kidney, spleen) }\end{array}$ & $\begin{array}{l}\mathrm{RC} / \mathrm{G} / \mathrm{H}, \mathrm{YC}, \mathrm{IT} \downarrow \\
\mathrm{GS}-\end{array}$ & {$[30,31]$} \\
\hline
\end{tabular}

LRRK2 is linked to the displayed pathways via interaction (I) with, phosphorylation (P) of or genetic interaction (GI) with the specific component of the pathway displayed in the second column. CHIP = C-terminus of HSP70-interacting protein; Co-IP = co-immunoprecipitation; DVL = dishevelled family of proteins; $\mathrm{EF} 1 \mathrm{~A}=$ elongation factor $1 \alpha ; \mathrm{FL}=$ full length; $\mathrm{GS}=\mathrm{G} 2019 \mathrm{~S}$; GSK $3 \beta=$ glycogen synthase kinase $3 \beta$; IT = I2012T; JIP = c-Jun $\mathrm{N}$-terminal kinase-interacting protein; $\mathrm{KD}=$ kinase dead; $\mathrm{kin}=$ kinase domain; MAPK = mitogen-activated protein kinase;
MKK = mitogen-activated protein kinase kinase; NA = not assessed; QUICK = quantitative immunoprecipitation combined with knockdown; RC/G/H = R1441C/G/H; RIP1 = receptor-interacting protein 1; Sgg = glycogen synthase kinase $3 \beta$ homolog Shaggy; TRADD = tumor necrosis factor receptor type 1-associated death domain protein; YC = Y1699C; YTH = yeast two-hybrid assay; $4 \mathrm{E}-\mathrm{BP}=4 \mathrm{E}$-binding protein; $-=$ no difference in $\mathrm{I} / \mathrm{P} /$ GI compared to wt; $\uparrow=$ increase in I/P/GI compared to $w t ; \downarrow=$ decrease in $\mathrm{I} / \mathrm{P} / \mathrm{GI}$ compared to wt. 
fore, it has been suggested that G2019S LRRK2-mediated neurite shortening in cultured cells and neurodegeneration in parkinsonian brains may be partly mediated by increased $\beta$-tubulin phosphorylation and constraining of microtubule dynamics [41]. In addition, a possible function of LRRK2 in the regulation of cytoskeleton dynamics has been proposed very recently, based on the interaction between LRRK2 and several actin isoforms as well as actin-associated proteins [43].

That LRRK2 might have a function in regulating microtubule dynamics is supported by the presence of phospho-tau-positive inclusion bodies in the brains of LRRK2 patients since tau is known as a microtubule-binding protein [44]. In addition, mislocalisation and altered phosphorylation of tau in LRRK2 G2019S cell culture and in vivo models has been reported $[24,41,45]$. Similar observations were made by MacLeod et al. [17] after viral vector-mediated delivery of the kinase domain of LRRK2 in the substantia nigra of mice with enhanced effects for the G2019S mutant. However, several independent studies have reported that tau is not a direct substrate of LRRK2 $[17,24,41,46]$. Therefore, it has been suggested that LRRK2 may have an indirect effect on the phosphorylation of tau, thereby contributing to the regulation of microtubule dynamics. This hypothesis has been supported very recently by the identification of the Drosophila glycogen synthase kinase $3 \beta$ homologue Shaggy as a linking kinase between LRRK2 G2019S-enhanced kinase activity and tau phosphorylation [24].

Another link between LRRK2 and microtubule polymerisation is provided by the interaction between LRRK2 and elongation factor $1 \alpha$ (EF1A) [47]. Besides its canonical role in mRNA translation, EF1A is involved in maintaining the stability of the microtubule cytoskeleton. The latter function has been shown to be impaired by LRRK2 in an in vitro microtubule polymerisation assay [47]. However, since this effect was similar for both wt and G2019S LRRK2, the functional interaction between LRRK2 and EF1A is unlikely to be related to G2019S LRRK2-linked PD.

Moesin is a member of the ERM family of proteins that plays a role in the anchoring of the actin cytoskeleton to the plasma membrane and the regulation of membrane structure and organisation [48]. Moesin was picked up as a LRRK2 substrate in a KESTREL (kinase substrate tracking and elucidation) screen performed on rat brain [49]. Further in vitro experiments demonstrated that moesin is phosphorylated by G2019S LRRK2 at Thr ${ }^{558}$, which fulfils a regulatory role in the binding of moesin to actin. The regulation of moesin phosphorylation by

On the Road to LRRK2 Signalling
LRRK2 has recently been supported by observations in primary neurons derived from inducible LRRK2 transgenic mice [23]. In this study, the reduction in neurite number and neurite length observed in G2019S LRRK2overexpressing neurons could be linked to an increased phosphorylation status of ERM proteins in the neuronal filopodia and an increase in actin polymerisation. On the other hand, deletion of LRRK2, which lowered the phospho-ERM and F-actin contents, promoted neurite outgrowth. However, no difference in phospho-ERM levels could be observed between LRRK2 wt-overexpressing neurons and neurons from non-transgenic mice despite an 8- to 16-fold difference in LRRK2 expression level. Therefore, the above observations are consistent with a gain-of-function mechanism of the G2019S mutant and support a model in which G2019S LRRK2 perturbs neuronal morphogenesis by altering the homeostasis of phosphorylated ERM proteins and F-actin in sprouting neurites.

Finally, LRRK2 has been linked to the cytoskeleton via its interaction with the dishevelled family of proteins (DVL1/2/3) [29]. The latter are key regulators of Wnt signalling pathways important for axon guidance, synapse formation and neuronal maintenance. Moreover, knockdown of LRRK2 in SH-SY5Y cells resulted in the upregulation of several genes involved in canonical Wnt signalling pathways [50]. The interaction between LRRK2 and DVL1 is mediated by the ROC-COR tandem and is almost completely abolished by introduction of the Y1699C mutant, whereas the $\mathrm{R} 1441 \mathrm{C} / \mathrm{G} / \mathrm{H}$ substitutions strengthen the interaction [29]. The study has also shown a functional link between LRRK2 and DVL1 in microtubule stabilisation. However, whether LRRK2 Y1699C and R1441C/G/H mutants differentially affect microtubule stabilisation or another Wnt signalling step still awaits further study. Nevertheless, the differential effects of the ROC and COR pathogenic mutants on the interaction with DVL1 might be supportive of a differential (pathogenic) effect of these mutants on Wnt signalling.

\section{LRRK2 and the Protein Translation Machinery}

$4 \mathrm{E}$-binding protein $(4 \mathrm{E}-\mathrm{BP})$ represses protein translation by binding to the eukaryotic initiation factor $4 \mathrm{E}$. Upon different intrinsic and extrinsic stress stimuli, 4E$\mathrm{BP}$ can dissociate from the complex after hyperphosphorylation, enabling a rapid change in protein translation. 4E-BP has been screened as an LRRK2 substrate based on a genetic interaction observed between LRRK2 (dLRRK) and the 4E-BP pathway in Drosophila melanogaster [51]. Subsequent in vitro and in vivo experiments 
showed phosphorylation of 4E-BP in an LRRK2 kinasedependent manner. The functional link between $4 \mathrm{E}-\mathrm{BP}$ and dLRRK is further supported by the rescue of mutant dLRRK phenotype by overexpression of 4E-BP in Drosophila [51] and the suppression of PTEN-induced putative kinase 1 (PINK1) and parkin mutant phenotypes in dLRRK knockout (KO) flies via the activation of $4 \mathrm{E}-\mathrm{BP}$ [52]. Nevertheless, $4 \mathrm{E}-\mathrm{BP}$ is only a poor direct substrate of LRRK2 in comparison with LRRK2 autophosphorylation or 4E-BP phosphorylation by other kinases [53]. Therefore, the functional relevance of the phosphorylation of 4E-BP by LRRK2 in mammalian organisms in vivo still awaits further experimental evidence.

\section{LRRK2 and Synaptic Vesicle Endocytosis}

Shin et al. [19] have reported an interaction of LRRK2 with Rab5b, a key regulator of endocytotic vesicular transport. This interaction was mediated by the LRR domain of LRRK2 and was not altered by the pathogenic R1441C and G2019S mutants. The authors observed a decrease in synaptic vesicle endocytosis in neurons after knockdown or overexpression of wt LRRK2 or the pathogenic mutants R1441C and G2019S. The latter effect could be rescued by overexpression of functionally active Rab5b. Therefore, it has been postulated that LRRK2 regulates synaptic vesicle endocytosis by interaction with Rab5b. This is supported by the vesicular trafficking defects observed in mouse primary cortical neurons overexpressing wt LRRK2 [9].

\section{LRRK2 and the Mitogen-Activated Protein Kinase Signalling Cascades}

The kinase domain of LRRK2 shares homology with receptor-interacting protein kinases and mixed-lineage kinases. Both of these kinase families participate in signalling events in response to cellular stress caused by various stimuli. In analogy to receptor-interacting protein kinase 1, evidence suggests that LRRK2 is involved in the transduction of death signals by interaction with FADD [16]. Several lines of evidence also hint at an involvement of LRRK2 in stress-induced signalling events, possibly by an interaction with mitogen-activated protein kinase (MAPK) signalling cascades, despite the fact that LRRK2 does not display the characteristic function of an MAPKactivating protein in vivo $[4,54]$.

The c-Jun N-terminal kinase (JNK) and p38 MAPK signalling cascades are activated by several MAPK kinase kinases, including mixed-lineage kinase 3, via the phosphorylation of mitogen-activated protein kinase kinase (MKK)4/7 and MKK3/6, respectively. In analogy,
LRRK2 has been shown to bind MKK3, 6 and 7 and to phosphorylate MKK3, 4, 6 and 7 [54, 55]. Furthermore, LRRK2 has also been shown to interact with the JNKinteracting proteins (JIP)1-3 and JIP4, which are scaffolding proteins that bring together MKK with MAPK involved in the JNK and p38 signalling cascades, respectively [56]. Moreover, the interaction between LRRK2 and MKK6 may have several functional implications for both proteins. First, coexpression not only increased steady-state levels of both proteins, but also increased MKK6 membrane association. Second, MKK6 and p38 are necessary for LRRK2-mediated protection against mitochondrial stress in Caenorhabditis elegans. Therefore, it can be speculated that LRRK2 functions as a scaffolding protein in a complex together with JIP and MKK to regulate p38/JNK signalling. However, whether this potential function of LRRK2 is related to PD is still unclear: LRRK2 G2019S, I2020T and R1441C mutants have been shown to increase LRRK2-MKK6 and LRRK2JIP4 binding, whereas the Y1699C mutation did not [54, 56].

Experimental evidence also points towards a potential involvement of LRRK2 in the extracellular signalregulated kinase (ERK)1/2 MAPK pathway. The ERK inhibitor U0126 can rescue LRRK2 G2019S-induced neurite shortening in differentiated SH-SY5Y cells [21]. Heo et al. [13] reported that the same inhibitor can rescue LRRK2 G2019S-induced cytotoxicity in SN4741 cells under $\mathrm{H}_{2} \mathrm{O}_{2}$ stress. Finally, Liou et al. [1] have found that LRRK2 can protect against oxidative stress by phosphorylation of ERK. Moreover, this effect was abolished in LRRK2 kinase deletion forms and the Y1699C pathogenic mutant.

\section{LRRK2 and Other PD-Linked Proteins}

Despite an initial report that LRRK2 can interact with parkin [25], this finding could not be replicated [57]. Therefore, it has been suggested that a possible interaction between LRRK2 and parkin might be indirect via CHIP, which has been shown to interact with both proteins $[38,39,58]$. Nevertheless, a functional link between LRRK2 and parkin is provided in the study by $\mathrm{Ng}$ et al. [59], in which G2019S LRRK2-induced neurodegeneration in a Drosophila model could be rescued by overexpression of parkin. Moreover, an extensive genetic linkage study in Drosophila has revealed a complex genetic interaction not only between LRRK 2 and parkin, but also between LRRK2 and the other PD-linked genes DJ-1 and PINK1 [60]. The link between LRRK2 and PINK1 has been suggested to be antagonistic based on a genetic in- 
Table 2. LRRK2 and lrk1 C. elegans models

\begin{tabular}{|c|c|c|}
\hline Transgene & Phenotype & Reference No. \\
\hline $\begin{array}{l}\text { lrk1 deletion/ } \\
\text { knockdown }\end{array}$ & mislocalisation of synaptic vesicles, mild chemotactic defects & {$[65]$} \\
\hline \multirow[t]{3}{*}{$\begin{array}{l}\text { LRRK2 } \\
\text { overexpression }\end{array}$} & $\begin{array}{l}\text { rotenone stress: rescue rotenone hypersensitivity, survival } \uparrow \text {, } \\
\text { DN survival } \uparrow \text {; mutant effect: G2019S, R1441C, KD < wt }\end{array}$ & {$[66,67]$} \\
\hline & basal conditions: age-dependent DN loss: G2019S, R1441C > wt & {$[66,68]$} \\
\hline & $\begin{array}{l}\text { dopaminergic-specific behavioural dysfunction; K1347A = Ntg; } \\
\text { G2019S, R1441C > wt; attenuated in lrk1-/- }\end{array}$ & {$[68]$} \\
\hline lrk1 overexpression & early larval arrest; wt and G1876S ( G2019S) & {$[61]$} \\
\hline
\end{tabular}

$\mathrm{DN}=$ Dopaminergic neuron; $\mathrm{ER}=$ endoplasmic reticulum; $\mathrm{KD}=$ kinase dead; $\mathrm{Ntg}=$ non-transgenic.

teraction study between lrk1 and PINK1 in C. elegans [61]. Supportive evidence for a functional interaction between LRRK2 and DJ-1 comes from the observation that DJ-1 can rescue G2019S LRRK2-induced cell death in a mouse dopaminergic cell line under oxidative stress [13]. However, whether these results are representative of specific functional interactions between LRRK 2 and parkin, PINK and DJ-1, or whether they are related to general neuroprotective effects assigned to parkin, PINK1 and DJ-1 is not clear to date.

Since LB have been found in the brains of most LRRK2 PD patients, it has been questioned whether there is a physical and/or functional interaction between LRRK2 and $\alpha$-synuclein. Although a small percentage of LB contains LRRK2, both proteins do not interact physically under basal conditions [26,62], although under oxidative stress, colocalisation, coimmunoprecipitation and upregulation of the protein levels of both LRRK2 and $\alpha$-synuclein were observed in HEK293T cells [62]. LRRK2 has been reported to phosphorylate $\alpha$-synuclein using crude cell extract as the source of kinase [32]; however, purified LRRK2 does not phosphorylate $\alpha$-synuclein $[35,46]$. Finally, no $\alpha$-synuclein aggregates have been found in brains of the transgenic LRRK2 animal models, although $\alpha$-synuclein inclusions were recently reported in the kidneys of LRRK2 KO mice [63] and in the brains of inducible LRRK2/ $\alpha$-synuclein A53T double-transgenic mice [64] (see below). These results point to a potential loose functional interaction between LRRK2 and $\alpha$-synuclein, whereby LRRK 2 can act in certain conditions as an upstream modulator of $\alpha$-synuclein pathology.

On the Road to LRRK2 Signalling

\section{LRRK2 in vivo Models}

\section{Elegans Models}

In contrast to mammals, which possess two LRRK proteins (LRRK1 and LRRK2), the nematode C. elegans contains only one LRRK2 homologue, namely lrk1 (GenBank accession No. WBGene00003068). The lrk1 protein shares 25/44\% (exact/positive matches) homology to LRRK2 over a region of approximately 1,300 amino acids including an LRR-ROC-COR-kin-WD40 sequence. An overview of LRRK-related C. elegans models is given in table 2.

lrk1 deletion worms display mislocalisation of synaptic vesicles in neurons accompanied by mild chemotactic defects [65], but they are identical to non-transgenics in other characteristics such as viability, mitochondrial integrity and axon guidance under basal conditions [61, 66]. However, lrk1 deletion or knockdown worms are highly sensitised to both endoplasmic reticulum stress and rotenone stress $[54,61,66,67]$. This phenotype could be rescued by overexpression of wt LRRK2 [66]. Moreover, bare overexpression of LRRK2 increased the survival rate and protected dopaminergic neurons under rotenone stress. This protective effect was more pronounced after overexpression of wt LRRK2; however, also LRRK2 G2019S, R1441C and kinase-dead mutants provided increased protection compared with non-transgenic worms $[66,67]$. Despite the protective effect of LRRK2 overexpression under rotenone stress, tests under basal conditions showed detrimental effects on C. elegans dopaminergic neuron survival. Age-dependent dopaminergic cell loss was seen after overexpression of wt LRRK2, which was exacerbated 
Table 3. LRRK 2 and dLRRK Drosophila models

\begin{tabular}{|c|c|c|}
\hline Transgene & Phenotype & $\begin{array}{l}\text { Reference } \\
\text { No. }\end{array}$ \\
\hline \multirow{4}{*}{$\begin{array}{l}\text { dLRRK deletion/ } \\
\text { knockdown }\end{array}$} & reduction in $\mathrm{TH}$ immunoreactivity, impaired locomotive activity & [69] \\
\hline & normal development and DN number & {$[45,70]$} \\
\hline & selective sensitivity to $\mathrm{H}_{2} \mathrm{O}_{2}$ & {$[70]$} \\
\hline & $\begin{array}{l}\text { reduced sensitivity to } \mathrm{H}_{2} \mathrm{O}_{2} \text { and paraquat, oxidative damage } \downarrow \text {, } \\
\text { dopamine content } \uparrow\end{array}$ & {$[45]$} \\
\hline \multirow[t]{2}{*}{$\begin{array}{l}\text { LRRK2 } \\
\text { overexpression }\end{array}$} & $\begin{array}{l}\text { retinal degradation, DN number } \downarrow \text {, lifespan } \downarrow \text {, locomotive problems; } \\
\text { G2019S > wt }\end{array}$ & {$[71]$} \\
\hline & $\begin{array}{l}\text { G2019S, Y1699C, G2385R: DN number } \downarrow \text {, lifespan } \downarrow \text {, locomotive problems } \\
\text { (G2019S and Y1699C), dopamine content } \downarrow \text { (G2019S), increased rotenone } \\
\text { sensitivity (G2019S and G2385R); wt = Ntg }\end{array}$ & {$[59]$} \\
\hline
\end{tabular}

$\mathrm{DN}=$ Dopaminergic neuron; $\mathrm{KD}=$ kinase dead; $\mathrm{Ntg}=$ non-transgenic $; \mathrm{TH}=$ tyrosine hydroxylase.

in the G2019S and R1441C mutants [66, 68]. In the study by Yao et al. [68], this neurodegeneration was reflected in dopaminergic-specific behavioural dysfunction that could be rescued by exogenous dopamine. Moreover, this parkinsonian phenotype was attenuated in an lrk1 KO background, and was even completely absent in LRRK2 GTP-binding-deficient K1347A transgenic worms [68]. Finally, one study has reported embryonic lethality of $C$. elegans overexpressing wt lrk1 and G1876S lrk1, corresponding to the G2019S mutation in LRRK2 [61]. Therefore, overexpression of lrk1 in C. elegans seems to be more detrimental than overexpression of LRRK2. This may be explained by differences in expression levels or worm strains but could also indicate inherent differences in the functioning of these protein homologues in C. elegans. Therefore, further research is required to better understand lrk1 function in C. elegans and how this relates to the function of human LRRK2.

\section{Drosophila Models}

The fruit fly, D. melanogaster, also contains one LRRK2 homologue, namely dLRRK (GenBank accession No. DQ494533). The dLRRK protein contains an LRR, ROC, COR and kinase domain, and is $24 \%$ identical and $38 \%$ similar to LRRK2. An overview of all LRRK2 and dLRRK Drosophila models is given in table 3.

To date, three different studies have been conducted on the effect of dLRRK deletion in Drosophila. One has reported that dLRRK2 deletion leads to impaired locomotor activity and a reduction in tyrosine hydroxylase immunoreactivity [69], whereas the other two have found no abnormalities in development or the number of dopaminergic neurons in these flies [51, 70]. The latter two studies differ in the response of dLRRK deletion flies to oxidative stress: Wang et al. [70] have reported an enhanced sensitivity to $\mathrm{H}_{2} \mathrm{O}_{2}$ stress while Imai et al. [51] have observed a reduction in sensitivity to general oxidative stress accompanied by reduced oxidative damage. Overexpression of wt dLRRK causes an increase in both oxidative stress sensitivity and oxidative damage without displaying any other gross abnormalities [51, 69]. Lee et al. [69] have reported no abnormalities in flies overexpressing the dLRRK mutant that corresponds to R1441C. On the other hand, the overexpression of both Y1699Cand I2020T-corresponding dLRRK mutants caused a reduction in the number of dopaminergic neurons and the dopamine content, and led to an increase in oxidative stress sensitivity and oxidative damage, whereas overexpression of a triple kinase-dead dLRRK mutant was indistinguishable from control flies [51]. Finally, two studies have assessed the effects of overexpression of human LRRK2 in Drosophila. These studies show that overexpression of G2019S LRRK2 causes age-dependent degeneration of dopaminergic neurons, locomotor problems and a reduced life span in these flies. However, both studies differ in the severity of the defects observed: Liu et al. 
Table 4. LRRK2 mouse models

\begin{tabular}{|c|c|c|}
\hline Transgene & Phenotype & Reference No \\
\hline \multirow{4}{*}{$\begin{array}{l}\text { mLRRK2 deletion/ } \\
\text { knockdown }\end{array}$} & no characterisation published & {$[37,72]$} \\
\hline & no abnormalities in development and dopaminergic system & {$[63,64,73]$} \\
\hline & no difference in MPTP sensitivity compared to Ntg & [73] \\
\hline & $\begin{array}{l}\text { kidneys: } \alpha \text {-synuclein accumulation and aggregation of ubiquitinated } \\
\text { proteins, impairment of protein degradation pathways, apoptosis }\end{array}$ & {$[63]$} \\
\hline \multirow[t]{4}{*}{ BAC hLRRK2 } & wt: no abnormalities & {$[74,75]$} \\
\hline & G2019S, Y1699C: no abnormalities & {$[74]$} \\
\hline & $\begin{array}{l}\text { R1441G: axonal pathology of nigrostriatal dopaminergic projections, } \\
\text { age-dependent and levodopa-responsive slowness of movement, } \\
\text { dopamine release } \downarrow \text {, no loss of DN in SN }\end{array}$ & {$[75]$} \\
\hline & $\begin{array}{l}\text { wt, G2019S: striatal dopamine } \downarrow \text {, tau alterations (more pronounced } \\
\text { in G2019S), abnormal exploratory behaviours (G2019S) }\end{array}$ & {$[52]$} \\
\hline \multirow[t]{2}{*}{ BAC mLRRK2 } & $\begin{array}{l}\text { wt: no obvious brain abnormalities, normal dopaminergic system, } \\
\text { dopamine release } \uparrow\end{array}$ & {$[76]$} \\
\hline & G2019S: no obvious brain abnormalities, striatal dopamine $\downarrow$ & {$[76]$} \\
\hline \multirow{2}{*}{$\begin{array}{l}\text { Inducible (CaMKII } \\
\text { promoter) hLRRK2 }\end{array}$} & G2019S: no obvious brain or motor abnormalities at $12 \mathrm{mnd}$ & {$[22]$} \\
\hline & $\begin{array}{l}\text { wt, G2019S: no gross neuropathological phenotype, Golgi } \\
\text { fragmentation, perturbed microtubule dynamics, impairment of } \\
\text { UPS, increased ambulatory activities (G2019S) }\end{array}$ & {$[64]$} \\
\hline $\begin{array}{l}\text { Inducible } \\
\text { (CaMKII promoter) } \\
\text { hLRRK2/ } \\
\alpha \text {-synuclein A53T }\end{array}$ & $\begin{array}{l}\text { wt, G2019S, KDD: dose-dependent exacerbation of } \alpha \text {-synuclein } \\
\text { neuropathology including } \alpha \text {-synuclein aggregation and cell loss; UPS } \\
\text { dysfunction, Golgi fragmentation, perturbation of microtubule dynamics, } \\
\text { mitochondrial abnormalities }\end{array}$ & {$[64]$} \\
\hline Knockin mLRRK2 & $\begin{array}{l}\text { R1441C: no obvious brain abnormalities, impairment of stimulated } \\
\text { dopamine neurotransmission and } \mathrm{D}_{2} \text { receptor function }\end{array}$ & {$[77]$} \\
\hline
\end{tabular}

CaMKII = Calcium/calmodulin-dependent protein kinase II- $\alpha$; DN = dopaminergic neurons; KDD = kinase domain deletion; mnd = month; MPTP = 1-methyl-4-phenyl-1,2,3,6-tetrahydropyridine; Ntg = non-transgenic; $\mathrm{SN}=$ substantia nigra; UPS = ubiquitin proteasome system.

[71] reported a more severe phenotype that was also observed to a lesser extent in the flies overexpressing $\mathrm{wt}$ LRRK, whereas Ng et al. [59] did not observe any abnormalities in the wt LRRK2 flies. The latter also reported an identical phenotype in Y1699C LRRK2 flies as in the G2019S flies.

In conclusion, these data show that overexpression of both mutant dLRRK and LRRK2 in Drosophila causes mild-to-severe dopaminergic neuron loss and dopaminergic defects. The severity of these defects shows variability from study to study, which might be explained by the use of different fly lines and expression systems (promoter, transgene). Finally, it seems that dLRRK and overexpressed LRRK2 also affect the regulation of the cellular stress response, although the underlying mechanism is unclear.

On the Road to LRRK2 Signalling

\section{Transgenic Mice}

The LRRK2 protein expressed in mice (mLRRK2) shares $86 \%$ homology to the human protein (GenBank accession No. NM_025730.3). Several transgenic mouse lines have been created to study the physiological function of LRRK2 and its relation to PD (table 4).

mLRRK2 seems to play little if any role in development and the survival of (dopaminergic) neurons since LRRK2 KO mice develop normally and display no abnormalities in their dopaminergic system $[63,64,72]$. In addition, LRRK2 KO mice are equally sensitive to the mitochondrial toxin 1-methyl-4-phenyl-1,2,3,6-tetrahydropyridine [72]. However, recently, Tong et al. [63] have reported gross age-dependent kidney abnormalities in mLRRK2 KO mice. The kidneys of these mice developed huge accumulation and aggregation of $\alpha$-synuclein and 
ubiquitinated proteins accompanied by a severe dysfunction of the autophagy-lysosomal machinery. The kidneys also displayed massive apoptotic cell death, oxidative damage and inflammatory response. These observations point towards an important function of mLRRK2 in the regulation of protein homeostasis during aging, at least in the kidneys [63]. Mice overexpressing human or mouse wt LRRK2, G2019S LRRK2 or Y1699C LRRK2 by means of BAC expression or inducible overexpression develop completely normally and do not display obvious brain abnormalities in most cases [64, 73-75]. However, the BAC wt and G2019S hLRRK2 mice characterised by Melrose et al. [45] presented with decreased striatal dopamine levels and tau alterations which were much more pronounced in case of the G2019S mice. The latter also displayed abnormalities in exploratory behaviours indicative of anxiety [45]. These observations do not completely conform with the study by Li et al. [73], which has reported elevated striatal dopamine release and enhanced performance in motor function tests of BAC transgenic wt mLRRK2 mice, whereas this phenotype was eliminated in the BAC G2019S mLRRK2 mice [73]. On the other hand, inducible overexpression of G2019S hLRRK2 in the mouse forebrain results in increased motor activity at 12 months of age, whereas the wt hLRRK2 mice do not display changes in motor behaviour [64]. BAC R1441G hLRRK2 mice develop a strong parkinsonian phenotype including age-dependent and levodopa-responsive slowness of movement associated with axonal pathology of nigrostriatal dopaminergic projections, although without loss of dopaminergic neurons [75]. Functional disturbance of the dopaminergic system is also evident in transgenic R1441C knockin mice, which display impairment of stimulated dopamine neurotransmission and $\mathrm{D}_{2}$ receptor function [76].

Although some of the LRRK2 transgenic mouse models developed to date recapitulate several cardinal locomotor and functional dopaminergic features of $\mathrm{PD}$, the two most important hallmarks of PD, namely age-dependent loss of dopaminergic neurons in the substantia nigra and deposition of $\alpha$-synuclein inclusion bodies, have not been observed. However, characterisation of double-transgenic mice, overexpressing both LRRK2 (wt, G2019S or kinase domain deleted) and $\alpha$-synuclein A53T in the forebrain regions, reveals that LRRK2 (wt, G2019S and kinase domain deleted) can enhance the progression of $\alpha$-synuclein-induced pathology including neuronal degeneration and abnormal somatic accumulation of $\alpha$-synuclein [64]. Mechanistically, the authors point towards LRRK2-induced dysfunction of endoplas- mic reticulum-Golgi-mediated protein/vesicle trafficking as a potential culprit in $\alpha$-synuclein-induced pathogenesis. Nevertheless, it is not clear whether LRRK2 directly induces the aggregation of $\alpha$-synuclein or rather interferes with the clearance of $\alpha$-synuclein by impairment of the proteasomal/lysosomal degradation pathways. The latter idea is supported by the fact that the severity of the phenotype is strongly correlated with the LRRK2 transgene expression level, whereas it seems independent of LRRK2 kinase activity. It is at least remarkable that genetic ablation of LRRK2 delayed $\alpha$-synuclein neuropathology in $\alpha$-synuclein A53T transgenic mice, whereas on the other hand, $\alpha$-synuclein accumulation and aggregation was highly increased in the kidneys of LRRK2 KO mice by impairment of the protein degradation pathways in the kidneys [63]. This fuels the idea that the interplay between LRRK2 and $\alpha$-synuclein is rather indirect, possibly via an alteration in protein degradation pathways, and may be strongly dependent on the cellular environment.

In conclusion, these observations in transgenic mice suggest that LRRK2 is not a critical determinant of the development and survival of (dopaminergic) neurons, but might rather be involved in the regulation of specific dopaminergic functions. Whether LRRK2 is important in the regulation of the stress response in mice is not evident from the current reports. However, LRRK2 seems to be involved in the autophagic-lysosomal system, at least in the kidney, and is associated with increased Golgi fragmentation and ubiquitin proteasome system dysfunction in the presence of $\alpha$-synuclein.

\section{Outlook}

Since the linkage of LRRK2 to the PARK8 locus in 2004 , intensive research efforts have been focused on the understanding of the physiological function of the protein and its relation to PD. The study of LRRK2 cell culture models, interaction partners, kinase substrates and animal models has led to the implication of LRRK2 in several major cell signalling pathways including apoptosis, the regulation of cytoskeleton dynamics, protein translation, MAPK signalling and the regulation of specific dopaminergic functions. However, whether and how these potential LRRK2 functions are related to LRRK2 pathogenicity in LRRK2 PD is still elusive to date. In order to deal with these pending questions, several important challenges still need to be addressed, including the validation of LRRK2 interaction partners 
and substrates as true in vivo determinants of LRRK2 functioning in health and disease. Also the elucidation of the link between LRRK2 biochemical and (patho) physiological functions, together with the elucidation of a three-dimensional crystal structure of LRRK2, will be crucial in order to pursue rational LRRK2 drug discovery/design. In addition, generation of more robust LRRK2 cell culture and animal models will greatly aid the in vivo validation of research hypotheses and the as- sessment of LRRK2 in a multifactorial context, including potentially modifying environmental and/or genetic factors, in PD.

\section{Acknowledgement}

This work was supported by the Fund for Scientific Research FWO Vlaanderen (G.0406.06, G.0666.09; postdoctoral fellowship to J.-M.T. and doctoral fellowships to V.D.).

\section{References}

1 Liou AK, Leak RK, Li L, Zigmond MJ: Wildtype LRRK2 but not its mutant attenuates stress-induced cell death via ERK pathway. Neurobiol Dis 2008;32:116-124.

- 2 Smith WW, Pei Z, Jiang H, Dawson VL, Dawson TM, Ross CA: Kinase activity of mutant LRRK2 mediates neuronal toxicity. Nat Neurosci 2006;9:1231-1233.

-3 Greggio E, Jain S, Kingsbury A, Bandopadhyay R, Lewis P, Kaganovich A, van der Brug MP, Beilina A, Blackinton J, Thomas KJ, Ahmad R, Miller DW, Kesavapany S, Singleton A, Lees A, Harvey RJ, Harvey K, Cookson MR: Kinase activity is required for the toxic effects of mutant LRRK2/dardarin. Neurobiol Dis 2006;23:329-341.

4 West AB, Moore DJ, Choi C, Andrabi SA, Li X, Dikeman D, Biskup S, Zhang Z, Lim KL, Dawson VL, Dawson TM: Parkinson's disease-associated mutations in LRRK2 link enhanced GTP-binding and kinase activities to neuronal toxicity. Hum Mol Genet 2007; 16:223-232.

5 Lee BD, Shin JH, VanKampen J, Petrucelli L, West AB, Ko HS, Lee YI, Maguire-Zeiss KA, Bowers WJ, Federoff HJ, Dawson VL, Dawson TM: Inhibitors of leucine-rich repeat kinase-2 protect against models of Parkinson's disease. Nat Med 2010;16:998-1000.

-6 Gloeckner CJ, Kinkl N, Schumacher A, Braun RJ, O'Neill E, Meitinger T, Kolch W, Prokisch H, Ueffing M: The Parkinson disease causing LRRK2 mutation I2020T is associated with increased kinase activity. Hum Mol Genet 2006;15:223-232.

7 Guo L, Gandhi PN, Wang W, Petersen RB, Wilson-Delfosse AL, Chen SG: The Parkinson's disease-associated protein, leucinerich repeat kinase 2 (LRRK2), is an authentic GTPase that stimulates kinase activity. Exp Cell Res 2007;313:3658-3670.

$\checkmark 8$ Lewis PA, Greggio E, Beilina A, Jain S, Baker A, Cookson MR: The R1441C mutation of LRRK2 disrupts GTP hydrolysis. Biochem Biophys Res Commun 2007;357:668-671.
Xiong Y, Coombes CE, Kilaru A, Li X, Gitler AD, Bowers WJ, Dawson VL, Dawson TM, Moore DJ: GTPase activity plays a key role in the pathobiology of LRRK2. PLoS Genet 2010;6:e1000902.

10 Daniëls V, Vancraenenbroeck R, Law BM, Greggio E, Lobbestael E, Gao F, de Maeyer M, Cookson MR, Harvey K, Baekelandt V, Taymans JM: Insight into the mode of action of the LRRK2 Y1699C pathogenic mutant. J Neurochem 2010;116:304-315.

11 Klein CL, Rovelli G, Springer W, Schall C, Gasser T, Kahle PJ: Homo- and heterodimerization of ROCO kinases: LRRK2 kinase inhibition by the LRRK2 ROCO fragment. J Neurochem 2009;111:703-715.

12 Li X, Moore DJ, Xiong Y, Dawson TM, Dawson VL: Reevaluation of phosphorylation sites in the Parkinson disease-associated leucine-rich repeat kinase 2. J Biol Chem 2010; 285:29569-29576.

13 Heo HY, Park JM, Kim CH, Han BS, Kim KS, Seol W: LRRK2 enhances oxidative stressinduced neurotoxicity via its kinase activity. Exp Cell Res 2010;316:649-656.

14 Iaccarino C, Crosio C, Vitale C, Sanna G, Carri MT, Barone P: Apoptotic mechanisms in mutant LRRK2-mediated cell death. Hum Mol Genet 2007;16:1319-1326.

15 Jorgensen ND, Peng Y, Ho CC, Rideout HJ, Petrey D, Liu P, Dauer WT: The WD40 domain is required for LRRK2 neurotoxicity. PloS One 2009;4:e8463.

16 Ho CC, Rideout HJ, Ribe E, Troy CM, Dauer WT: The Parkinson disease protein leucinerich repeat kinase 2 transduces death signals via Fas-associated protein with death domain and caspase- 8 in a cellular model of neurodegeneration. J Neurosci 2009;29: 1011-1016.

17 MacLeod D, Dowman J, Hammond R, Leete $\mathrm{T}$, Inoue K, Abeliovich A: The familial parkinsonism gene LRRK2 regulates neurite process morphology. Neuron 2006;52:587593.
8 Tan EK, Zhao Y, Skipper L, Tan MG, di Fonzo A, Sun L, Fook-Chong S, Tang S, Chua E, Yuen Y, Tan L, Pavanni R, Wong MC, Kolatkar P, Lu CS, Bonifati V, Liu JJ: The LRRK2 Gly2385Arg variant is associated with Parkinson's disease: genetic and functional evidence. Hum Genet 2007;120:857-863.

19 Shin N, Jeong H, Kwon J, Heo HY, Kwon JJ, Yun HJ, Kim CH, Han BS, Tong Y, Shen J, Hatano T, Hattori N, Kim KS, Chang S, Seol W: LRRK2 regulates synaptic vesicle endocytosis. Exp Cell Res 2008;314:2055-2065.

20 Sen S, Webber PJ, West AB: Dependence of leucine-rich repeat kinase 2 (LRRK2) kinase activity on dimerization. J Biol Chem 2009; 284:36346-36356.

21 Plowey ED, Cherra SJ 3rd, Liu YJ, Chu CT: Role of autophagy in G2019S-LRRK2-associated neurite shortening in differentiated SH-SY5Y cells. J Neurochem 2008; 105: 1048-1056.

22 Wang L, Xie C, Greggio E, Parisiadou L, Shim H, Sun L, Chandran J, Lin X, Lai C, Yang WJ, Moore DJ, Dawson TM, Dawson VL, Chiosis G, Cookson MR, Cai H: The chaperone activity of heat shock protein 90 is critical for maintaining the stability of leucine-rich repeat kinase 2. J Neurosci 2008;28: 3384-3391.

23 Parisiadou L, Xie C, Cho HJ, Lin X, Gu XL, Long CX, Lobbestael E, Baekelandt V, Taymans JM, Sun L, Cai H: Phosphorylation of ezrin/radixin/moesin proteins by LRRK2 promotes the rearrangement of actin cytoskeleton in neuronal morphogenesis. J Neurosci 2009;29:13971-13980.

24 Lin CH, Tsai PI, Wu RM, Chien CT: LRRK2 G2019S mutation induces dendrite degeneration through mislocalization and phosphorylation of tau by recruiting autoactivated GSK3ß. J Neurosci 2010;30:13138-13149.

25 Smith WW, Pei Z, Jiang H, Moore DJ, Liang Y, West AB, Dawson VL, Dawson TM, Ross CA: Leucine-rich repeat kinase 2 (LRRK2) interacts with parkin, and mutant LRRK2 induces neuronal degeneration. Proc Natl Acad Sci USA 2005;102:18676-18681. 
26 Waxman EA, Covy JP, Bukh I, Li X, Dawson TM, Giasson BI: Leucine-rich repeat kinase 2 expression leads to aggresome formation that is not associated with $\alpha$-synuclein inclusions. J Neuropathol Exp Neurol 2009;68: 785-796.

$\checkmark 27$ Alegre-Abarrategui J, Christian H, Lufino MM, Mutihac R, Venda LL, Ansorge O, Wade-Martins R: LRRK2 regulates autophagic activity and localizes to specific membrane microdomains in a novel human genomic reporter cellular model. Hum Mol Genet 2009; 18:4022-4034.

28 Greggio E, Lewis PA, van der Brug MP, Ahmad R, Kaganovich A, Ding J, Beilina A, Baker AK, Cookson MR: Mutations in LRRK2/dardarin associated with Parkinson disease are more toxic than equivalent mutations in the homologous kinase LRRK1. J Neurochem 2007;102:93-102.

29 Sancho RM, Law BM, Harvey K: Mutations in the LRRK2 Roc-COR tandem domain link Parkinson's disease to Wnt signalling pathways. Hum Mol Genet 2009;18:39553968.

>30 Dzamko N, Deak M, Hentati F, Reith AD, Prescott AR, Alessi DR, Nichols RJ: Inhibition of LRRK2 kinase activity leads to dephosphorylation of $\mathrm{Ser}^{910} / \mathrm{Ser}^{935}$, disruption of 14-3-3 binding and altered cytoplasmic localization. Biochem J 2010;430:405-413.

>31 Nichols RJ, Dzamko N, Morrice NA, Campbell DG, Deak M, Ordureau A, Macartney T, Tong Y, Shen J, Prescott AR, Alessi DR: 14-33 binding to LRRK2 is disrupted by multiple Parkinson's disease-associated mutations and regulates cytoplasmic localization. Biochem J 2010;430:393-404.

>32 Qing H, Wong W, McGeer EG, McGeer PL: Lrrk2 phosphorylates alpha synuclein at serine 129: Parkinson disease implications. Biochem Biophys Res Commun 2009;387:149152.

-33 Rudenko IN, Cookson MR: 14-3-3 proteins are promising LRRK2 interactors. Biochem J 2010;430:e5-e6.

>34 Dächsel JC, Behrouz B, Yue M, Beevers JE, Melrose HL, Farrer MJ: A comparative study of Lrrk2 function in primary neuronal cultures. Parkinsonism Relat Disord 2010;16: 650-655.

-35 Li X, Tan YC, Poulose S, Olanow CW, Huang $\mathrm{XY}$, Yue Z: Leucine-rich repeat kinase 2 (LRRK2)/PARK8 possesses GTPase activity that is altered in familial Parkinson's disease R1441C/G mutants. J Neurochem 2007;103: 238-247.

-36 Ohta E, Katayama Y, Kawakami F, Yamamoto M, Tajima K, Maekawa T, Iida N, Hattori $\mathrm{S}$, Obata F: $\mathrm{I}^{2020} \mathrm{~T}$ leucine-rich repeat kinase 2 , the causative mutant molecule of familial Parkinson's disease, has a higher intracellular degradation rate than the wild-type molecule. Biochem Biophys Res Commun 2009; 390:710-715.
37 Dächsel JC, Taylor JP, Mok SS, Ross OA, Hinkle KM, Bailey RM, Hines JH, Szutu J, Madden B, Petrucelli L, Farrer MJ: Identification of potential protein interactors of Lrrk2. Parkinsonism Relat Disord 2007;13: 382-385.

38 Ko HS, Bailey R, Smith WW, Liu Z, Shin JH, Lee YI, Zhang YJ, Jiang H, Ross CA, Moore DJ, Patterson C, Petrucelli L, Dawson TM, Dawson VL: CHIP regulates leucine-rich repeat kinase-2 ubiquitination, degradation, and toxicity. Proc Natl Acad Sci USA 2009; 106:2897-2902.

39 Ding X, Goldberg MS: Regulation of LRRK2 stability by the E3 ubiquitin ligase CHIP. PloS One 2009;4:e5949.

40 Gandhi PN, Wang X, Zhu X, Chen SG, Wilson-Delfosse AL: The Roc domain of leucine-rich repeat kinase 2 is sufficient for interaction with microtubules. J Neurosci Res 2008;86:1711-1720.

41 Gillardon F: Leucine-rich repeat kinase 2 phosphorylates brain tubulin- $\beta$ isoforms and modulates microtubule stability: a point of convergence in parkinsonian neurodegeneration? J Neurochem 2009;110:15141522 .

42 Gandhi PN, Chen SG, Wilson-Delfosse AL: Leucine-rich repeat kinase 2 (LRRK2): a key player in the pathogenesis of Parkinson's disease. J Neurosci Res 2009;87:1283-1295.

43 Meixner A, Boldt K, van Troys M, Askenazi M, Gloeckner CJ, Bauer M, Marto JA, Ampe C, Kinkl N, Ueffing M: A QUICK screen for Lrrk2 interaction partners: leucine-rich repeat kinase 2 is involved in actin cytoskeleton dynamics. Mol Cell Proteomics 2010; 10:M110.001172.

44 Taymans JM, Cookson MR: Mechanisms in dominant parkinsonism: the toxic triangle of LRRK2, $\alpha$-synuclein, and tau. Bioessays 2010;32:227-235.

45 Melrose HL, Dächsel JC, Behrouz B, Lincoln SJ, Yue M, Hinkle KM, Kent CB, Korvatska E, Taylor JP, Witten L, Liang YQ, Beevers JE, Boules M, Dugger BN, Serna VA, Gaukhman A, Yu X, Castanedes-Casey M, Braithwaite AT, Ogholikhan S, Yu N, Bass D, Tyndall G, Schellenberg GD, Dickson DW, Janus C, Farrer MJ: Impaired dopaminergic neurotransmission and microtubule-associated protein tau alterations in human LRRK2 transgenic mice. Neurobiol Dis 2010;40:503-517.

46 West AB, Moore DJ, Biskup S, Bugayenko A, Smith WW, Ross CA, Dawson VL, Dawson TM: Parkinson's disease-associated mutations in leucine-rich repeat kinase 2 augment kinase activity. Proc Natl Acad Sci USA 2005;102:16842-16847.

47 Gillardon F: Interaction of elongation factor 1 - $\alpha$ with leucine-rich repeat kinase 2 impairs kinase activity and microtubule bundling in vitro. Neuroscience 2009;163:533-539.

48 Mangeat P, Roy C, Martin M: ERM proteins in cell adhesion and membrane dynamics. Trends Cell Biol 1999;9:187-192.
49 Jaleel M, Nichols RJ, Deak M, Campbell DG, Gillardon F, Knebel A, Alessi DR: LRRK2 phosphorylates moesin at threonine-558: characterization of how Parkinson's disease mutants affect kinase activity. Biochem J 2007;405:307-317.

50 Häbig K, Walter M, Poths S, Riess O, Bonin M: RNA interference of LRRK2-microarray expression analysis of a Parkinson's disease key player. Neurogenetics 2008;9:83-94.

51 Imai Y, Gehrke S, Wang HQ, Takahashi R, Hasegawa K, Oota E, Lu B: Phosphorylation of $4 \mathrm{E}-\mathrm{BP}$ by LRRK 2 affects the maintenance of dopaminergic neurons in Drosophila. Embo J 2008;27:2432-2443.

52 Tain LS, Mortiboys H, Tao RN, Ziviani E, Bandmann O, Whitworth AJ: Rapamycin activation of $4 \mathrm{E}-\mathrm{BP}$ prevents parkinsonian dopaminergic neuron loss. Nat Neurosci 2009;12:1129-1135.

- 53 Kumar A, Greggio E, Beilina A, Kaganovich A, Chan D, Taymans JM, Wolozin B, Cookson MR: The Parkinson's disease associated LRRK2 exhibits weaker in vitro phosphorylation of 4E-BP compared to autophosphorylation. PloS One 2010;5:e8730.

54 Hsu CH, Chan D, Greggio E, Saha S, Guillily MD, Ferree A, Raghavan K, Shen GC, Segal L, Ryu H, Cookson MR, Wolozin B: MKK6 binds and regulates expression of Parkinson's disease-related protein LRRK2. J Neurochem 2010;112:1593-1604.

55 Gloeckner CJ, Schumacher A, Boldt K, Ueffing $\mathrm{M}$ : The Parkinson disease-associated protein kinase LRRK2 exhibits MAPKKK activity and phosphorylates MKK3/6 and MKK4/7, in vitro. J Neurochem 2009;109: 959-968.

56 Hsu CH, Chan D, Wolozin B: LRRK2 and the stress response: interaction with MKKs and JNK-interacting proteins. Neurodegener Dis 2010;7:68-75.

57 Dächsel JC, Mata IF, Ross OA, Taylor JP, Lincoln SJ, Hinkle KM, Huerta C, Ribacoba R, Blazquez M, Alvarez V, Farrer MJ: Digenic parkinsonism: investigation of the synergistic effects of PRKN and LRRK2. Neurosci Lett 2006;410:80-84.

58 Imai Y, Soda M, Hatakeyama S, Akagi T, Hashikawa T, Nakayama KI, Takahashi R: CHIP is associated with Parkin, a gene responsible for familial Parkinson's disease, and enhances its ubiquitin ligase activity. Mol Cell 2002;10:55-67.

59 Ng CH, Mok SZ, Koh C, Ouyang X, Fivaz ML, Tan EK, Dawson VL, Dawson TM, Yu F, Lim KL: Parkin protects against LRRK2 G2019S mutant-induced dopaminergic neurodegeneration in Drosophila. J Neurosci 2009;29:11257-11262. 
-60 Venderova K, Kabbach G, Abdel-Messih E, Zhang Y, Parks RJ, Imai Y, Gehrke S, Ngsee J, Lavoie MJ, Slack RS, Rao Y, Zhang Z, Lu B, Haque ME, Park DS: Leucine-rich repeat $k i$ nase 2 interacts with Parkin, DJ-1 and PINK1 in a Drosophila melanogaster model of Parkinson's disease. Hum Mol Genet 2009;18: 4390-4404.

-61 Sämann J, Hegermann J, von Gromoff E, Eimer S, Baumeister R, Schmidt E: Caenorhabditits [sic!] elegans LRK-1 and PINK-1 act antagonistically in stress response and neurite outgrowth. J Biol Chem 2009;284:1648216491.

62 Qing H, Zhang Y, Deng Y, McGeer EG, McGeer PL: Lrrk2 interaction with $\alpha$-synuclein in diffuse Lewy body disease. Biochem Biophys Res Commun 2009;390:1229-1234.

-63 Tong Y, Yamaguchi H, Giaime E, Boyle S, Kopan R, Kelleher RJ 3rd, Shen J: Loss of leucine-rich repeat kinase 2 causes impairment of protein degradation pathways, accumulation of $\alpha$-synuclein, and apoptotic cell death in aged mice. Proc Natl Acad Sci USA 2010 107:9879-9884.

-64 Lin X, Parisiadou L, Gu XL, Wang L, Shim $\mathrm{H}$, Sun L, Xie C, Long CX, Yang WJ, Ding J, Chen ZZ, Gallant PE, Tao-Cheng JH, Rudow G, Troncoso JC, Liu Z, Li Z, Cai H: Leucinerich repeat kinase 2 regulates the progression of neuropathology induced by Parkinson'sdisease-related mutant $\alpha$-synuclein. Neuron 2009;64:807-827.

65 Sakaguchi-Nakashima A, Meir JY, Jin Y, Matsumoto K, Hisamoto N: LRK-1, a C. elegans PARK8-related kinase, regulates axonal-dendritic polarity of SV proteins. Curr Biol 2007;17:592-598.
66 Saha S, Guillily MD, Ferree A, Lanceta J, Chan D, Ghosh J, Hsu CH, Segal L, Raghavan K, Matsumoto K, Hisamoto N, Kuwahara T, Iwatsubo T, Moore L, Goldstein L, Cookson M, Wolozin B: LRRK2 modulates vulnerability to mitochondrial dysfunction in $\mathrm{Cae}$ norhabditis elegans. J Neurosci 2009;29: 9210-9218.

67 Wolozin B, Saha S, Guillily M, Ferree A, Riley $\mathrm{M}$ : Investigating convergent actions of genes linked to familial Parkinson's disease. Neurodegener Dis 2008;5:182-185.

68 Yao C, El Khoury R, Wang W, Byrd TA, Pehek EA, Thacker C, Zhu X, Smith MA, Wilson-Delfosse AL, Chen SG: LRRK2-mediated neurodegeneration and dysfunction of dopaminergic neurons in a Caenorhabditis elegans model of Parkinson's disease. Neurobiol Dis 2010;40:73-81.

69 Lee SB, Kim W, Lee S, Chung J: Loss of LRRK2/PARK8 induces degeneration of dopaminergic neurons in Drosophila. Biochem Biophys Res Commun 2007;358:534-539.

70 Wang D, Tang B, Zhao G, Pan Q, Xia K, Bodmer R, Zhang Z: Dispensable role of Drosophila ortholog of LRRK2 kinase activity in survival of dopaminergic neurons. Mol Neurodegener 2008;3:3.

71 Liu Z, Wang X, Yu Y, Li X, Wang T, Jiang H, Ren Q, Jiao Y, Sawa A, Moran T, Ross CA, Montell C, Smith WW: A Drosophila model for LRRK2-linked parkinsonism. Proc Natl Acad Sci USA 2008;105:2693-2698.
72 Andres-Mateos E, Mejias R, Sasaki M, Li X, Lin BM, Biskup S, Zhang L, Banerjee R, Thomas B, Yang L, Liu G, Beal MF, Huso DL, Dawson TM, Dawson VL: Unexpected lack of hypersensitivity in LRRK2 knock-out mice to MPTP (1-methyl-4-phenyl-1,2,3,6tetrahydropyridine). J Neurosci 2009;29: 15846-15850.

73 Li X, Patel JC, Wang J, Avshalumov MV, Nicholson C, Buxbaum JD, Elder GA, Rice ME, Yue Z: Enhanced striatal dopamine transmission and motor performance with LRRK2 overexpression in mice is eliminated by familial Parkinson's disease mutation G2019S. J Neurosci 2010;30:1788-1797.

74 Melrose HL, Kent CB, Taylor JP, Dächsel JC, Hinkle KM, Lincoln SJ, Mok SS, Culvenor JG, Masters CL, Tyndall GM, Bass DI, Ahmed Z, Andorfer CA, Ross OA, Wszolek ZK, Delldonne A, Dickson DW, Farrer MJ: A comparative analysis of leucine-rich repeat kinase 2 (Lrrk2) expression in mouse brain and Lewy body disease. Neuroscience 2007; 147:1047-1058

75 Li Y, Liu W, Oo TF, Wang L, Tang Y, JacksonLewis V, Zhou C, Geghman K, Bogdanov M, Przedborski S, Beal MF, Burke RE, Li C: Mutant $L R R K 2^{R 1441 G} \mathrm{BAC}$ transgenic mice recapitulate cardinal features of Parkinson's disease. Nat Neurosci 2009;12:826-828.

76 Tong Y, Pisani A, Martella G, Karouani M, Yamaguchi H, Pothos EN, Shen J: R1441C mutation in LRRK2 impairs dopaminergic neurotransmission in mice. Proc Natl Acad Sci USA 2009;106:14622-14627. 